\title{
DYNAMICS AND ADAPTATION OF THE PHUAN ETHNIC GROUP IN THAILAND
}

\author{
Ratchapan Karapan ${ }^{1 *} \&$ Panot Susuwan ${ }^{2}$ \\ *First and corresponding author \\ ${ }^{1}$ Centre of Tourism Research, Social Research Institute, Chiang Mai University, \\ Thailand \\ ${ }^{2}$ Broadcasting and Digital Journalism Department, School of Communication \\ Arts, Bangkok University, Thailand \\ (rkarapan286@gmail.com, yimmyjr@gmail.com) \\ DOI: https:/doi.org/10.22452/jati.vol26no1.7
}

\begin{abstract}
This is an examination of the continued dynamics and adaptation of the Phuan ethnic group in Thailand, especially how their customs have changed according to evolving social and environmental conditions. The objective was to understand the factors that have affected the dynamics and adaptation of the group in order to analyse the inheritance of their cultural practices and encourage accurate dissemination of Phuan traditional knowledge. A qualitative research method was used in four Phuan communities from different regions of Thailand. Data was gathered from observations, interviews and documentary research. The findings indicate that there are significant similarities between the cultural adaptations of Phuan people in each of the four areas, although there are also notable regional differences. There are dangers of staged authenticity in the pursuit of cultural conservation, especially through provincial or regional exhibitions. Instead, the researchers recommend a more participatory and organic approach.
\end{abstract}

Keywords: cultural conservation, cultural dynamics, ethnicity, heritage, Phuan

\section{Introduction and Background}

Tai Phuan is the name given to an ethnic group originating in the Lao People's Democratic Republic (Lao PDR). The word Tai means people. The word Phuan means high altitude or plateau. There is a general consensus within literature on the Tai Phuan people that they originated from Muang Phuan, a historical principality on the Xiangkhoang Plateau that constitutes the modern territory of Xiangkhouang Province in eastern Lao PDR (Ar-romsuk, 1978; Sirasoonthorn, 
Satean, Khamunee, \& Pirasan, 2016). The migration patterns of the Tai Phuan to Thailand is less accepted. Depending on the designation of the phases, the scope of the research or the intention of the scholar, the number of migration waves varies from two to six (Breazeale, 2012; Singsawat, 2017; Wittayapak, 2003). However, for the purposes of this investigation it is sufficient to understand that the most intense period of relocation occurred as the Siamese Kingdom asserted its dominance over the Lao peoples in the late-eighteenth and nineteenth centuries. When Tai Phuan families migrated (or were forcibly relocated) into the territory now known as Thailand, they became colloquially known as the Lao Phuan, implying that they originated from the Kingdom of Laos. Thai Phuan (with an ' $h$ ' in Thai) was then subsequently adopted to refer to their domicile within Thailand. Hereafter, the authors will use the term Phuan to reference the Thai Phuan communities studied in this investigation.

By moving to lands governed by the Siamese and Thai Kingdoms, the Phuan people have been forced to adapt to government directives and regulations aimed at their acculturation (Draper at al., 2019). In the first instance, authorities sought to protect their labour force by granting former Lao war captives Siamese citizenship, thus denying any French imperial claims to those people (Breazeale \& Smuckarn, 1988; van Roy, 2009). Following a period of economic exploitation of minorities in labour programmes, rapid political, economic and social changes were experienced by the Phuan upon the advent of the first national economic and social development plan (1961-1966) (Sermcheep, 2012). This was a concerted government effort to reduce the education and wealth gap between urban and rural society, and to improve national infrastructure in the wake of the Second World War. The directive was presented as an opportunity for rural people, especially ethnic minorities such as the Phuan, who subsequently dispersed across the country, settling and marrying in different regions. The efficacy of positively packaged government policies towards minorities has been recognised as a major factor in both suppression of ethnic nationalism and successful construction of a homogenous Thai nation (Burusapatana \& Atipas, 1988). This is despite clear structural ethnic inequalities in Thailand that make the Phuan people one of the most deprived groups in the country (Draper \& Selway, 2019).

Those who did relocate took their culture with them and, consequently, traditional Phuan practices and festivals were maintained in different locations across Thailand. This was further enabled through the work of the National Thai Phuan Association, which was established at Amarin Tararam Temple, Bangkok in 1975. The association has a network of members from 25 clubs distributed through 23 provinces nationwide. The objectives are to provide a meeting place 
for social functions, to coordinate relationships between the Thai Phuan people, to provide mutual assistance, to promote education, to provide public benefit, to promote the restoration and maintenance of traditions and to avoid political discussions. The association meets annually and provincial clubs rotate the hosting responsibilities. Furthermore, representatives from Xiangkhouang are invited to attend each year in order to maintain links to the traditional homeland of the Phuan people. The formation and activities of the National Thai Phuan Association are examples of how the Phuan have tried to maintain their heritage whilst also adapting to life in Thailand (Vichiranon, Sangoupong, Suthapannakul, \& Wangvanitchaphan, 2013).

For this investigation, the researchers were keen to examine the continued dynamics and adaptation of the Phuan ethnic group, especially how their customs have changed according to evolving social and environmental conditions. The objective was to understand the factors that have affected the dynamics and adaptation of the group in order to analyse the inheritance of their cultural practices and encourage accurate dissemination of Phuan traditional knowledge.

\section{Literature Review}

According to Breazeale (1975), the process of 'Thai-ification' began as a deliberate government mission to integrate minority groups into the Siamese state. Studies by Breazeale (1975), Diller (2002) and Draper et al. (2019) show that the multilayered process was carried out in a number of ways. These included introducing taxes, reducing indigenous social hierarchy, imposing administrative reforms that developed a national bureaucracy, forming a national boy scout movement and institutionalising mandatory military service, restructuring the national education system, encouraging ceremonies based on Central Thai culture, and suppressing minority religious calendars and spiritualism.

Research by Draper at al. (2019), Hesse-Swain (2011), Iijima (2018), and Lefferts and Cate (2012) shows that since the beginning of the twentieth century, ethnic groups in Thailand have been subsumed into regional geonyms based on Bangkok's central location: Isan, the North or the South. Domestic academics and the people themselves have also adopted these distinctions (Keyes, 2014). However, Alexander and McCargo (2014) assert that, because ethnic assimilation also affected people of the majority Tai group living in these geographic regions, inclusion of minorities in the Thai national identity was only a partial process. Consequently, 'complex, contested ethno-regional identit[ies]' emerged on linguistic continua between Thai and, variously, Lao, Malay and Burmese (Enfield, 2002; McCargo and Hongladarom, 2004). Bunnag's (1968) work reveals that, 
officially, the government considers most ethnic minorities within the country to be a subgroup of the Tai and speak a dialect of the national language, whilst academic and foreign sources like McCargo and Hongladarom (2004) more commonly identify distinct ethnic differences.

Despite reluctance to celebrate ethnic identity in Thailand, there is lowlevel recognition of the importance of cultural heritage preservation (Lertcharnrit \& Niyomsap, 2020). Sangchumnong and Kozak (2018) assert that this is largely due to the potential economic boost provided by the growing phenomenon of cultural tourism. Indeed, the most successful examples of cultural conservation programmes in Thailand are those that have promised tangible economic value for the communities in which they are based (Makpa, 2017). Research by Draper et al. (2019) shows that ethnic tourism in previously avoided indigenous communities is now popular. There is hope that socio-economic stimuli, such as the government-driven One Tambon One Product initiative that emphasises the unique qualities of local, often indigenous hand-made produce, will encourage a revival of pluralism in Thailand not seen since the days of the Kingdom of Siam. However, according to locals interviewed by Panupat, Gulthawatvichai and Karnjanakit, (2019), previous attempts at ethnic tourism in Thai Phuan communities have proven unsuccessful, due to inadequate infrastructure investment and lack of interest from Phuan people. Tumad \& Siriwong (2017) have also identified financial constraints as significant obstacles to the preservation of traditional culture in Thai Phuan communities.

In many local initiatives that promote culture as an attractive tourist commodity, its dynamism is often overlooked (Burns, 2001). Culture is not static. Both Ivanovic (2008) and Taylor (2001) show that by preserving traditional practices and exhibiting a staged authenticity out of the socio-cultural context, tourism initiatives succeed in creating an impression of superiority over nonmainstream cultures. Dolezal (2011) adds that development for tourism does encourage progress, but only until threats to the exotic "otherness" emerge. The culture must retain its tourism appeal at all costs, even if that restricts the organic development that may occur due to globalisation and the influences that the tourism brings (van der Duim, Peters, \& Wearing, 2005). It is therefore critical that authorities embrace original, past culture as well as continuously evolving modern culture. Kashima (2014) argues that there must be recognition of cultural dynamics, 'the formation, maintenance, and transformation of cultures over time'. However, in order for that to happen within Thai Phuan communities, there must first be systematic investigation of Thai Phuan cultural dynamics. This is a significant gap in the relatively small body of current academic research related to 
this Southeast Asian ethnic group. The researchers consequently designed the present investigation to provide a more detailed appraisal of the cultural dynamics of the Phuan people.

\section{Research Methodology}

This was a twelve-month qualitative investigation to analyse the relationship between the Phuan ethnic group, their traditional culture and their surrounding environment. Data was collected from documents and field study. The research area was specifically selected using a purposive sampling method. The chosen locations were communities within Thailand with a resident Phuan population that continued to practice some form of the cultures, beliefs and traditions associated with the ethnic group. Only those communities within convenient travelling distance for the researchers were approached and only those willing to cooperate with the investigation were finally selected. The final four communities were 1) Thung Hong Village, Thung Hong Sub-District, Mueang District, Phrae Province; 2) Thon Village, Ban Phue Sub-District, Ban Phue District, Udon Thani Province; 3) Ta Talat Village, Wat Bot Sub-District, Bang Pla Ma District, Suphanburi Province; and 4) Mab Pla Kao Village, Mab Pla Kao Sub-District, Tha Yang District, Phetchaburi Province. There were two target groups within the villages. The first group, key informants, was composed of individuals able to provide a high level of detail regarding Phuan culture, such as community leaders, academics and village elders. The second group, general informants, was composed of people living in the local communities, both of Phuan ethnic origin and of other ethnic origins.

Documentary data was collected from a variety of domestic and international academic literature, as well as local sources held by related institutions, agencies and organisations working in connection with the Phuan people. These included the National Thai Phuan Association, Chalermrat Culture Centre in Thung Hong Nuea, Phrae Provincial Thai Phuan Association, Udon Thani Provincial Thai Phuan Association, Suphanburi Provincial Thai Phuan Association, and Phetchaburi Provincial Thai Phuan Association. Field data was gathered from the four identified communities, as well as from individuals representing the National Thai Phuan Association and each of the four aforementioned provincial chapters.

In the field, data was collected by making field notes, taking still images and recording videos during periods of participant and non-participant observation. Non-participant observation was conducted at the beginning of each foray into the field and during any activities in which the researchers were unable 
to participate. Whenever possible, the researchers joined in with every day and cultural activities, recording notes on the practices, behaviours, relationships and meanings. The researchers asked questions throughout this participation to supplement the note taking. In addition to observation, unstructured interviews were held with informants to supplement the field notes and create a fuller picture of understanding. All interviews were audio and video-recorded.

Data was categorised according to the aims of the investigation and summarised ready for a two-step analysis process (Chantavanich, 2004). First, analytic induction was undertaken to interpret research findings and refine the working hypothesis of the investigation. Second, three typologies were identified and analysed together. The first typology comprised data gathered from documents related to the dynamics and adjustment of the Phuan ethnic group. The second typology comprised data gathered from the field regarding the dynamics and adaptation of the Phuan ethnic group. The third and final typology comprised data concerning the dissemination of knowledge produced by the Phuan ethnic group and academic conferences regarding Phuan culture.

\section{Results}

\section{Origins}

The four Phuan communities examined in this investigation have unique settlement stories. The original inhabitants of Thung Hong Village came to Phrae in 1834 and seventeen Phuan families were granted permission by the city governor to settle outside the city walls near the main horse gate. As the area was not suitable for farming, the families constructed their main temple further north. A second religious structure was subsequently created when the people found better land for constructing residential homes on the site now known as Thung Hong Village. There are consequently two separate temples serving the residents.

Unlike the single community that relocated to Phrae, the villagers of Thon Village in Udon Thani Province are descended from two different groups. The first group immigrated to Thailand during the reign of King Rama III in 1827 and settled near the Mekong River. The second group fled Ban Mi District in Lopburi Province, wanting to escape hostile Yunnanese merchants. The two groups combined and formed a single community in Phue forest, calling their new village Ban Phue. Nowadays, all Phuan people in Udon Thani Province are referred to as Phuan Ban Phue, whether they live in Ban Phue or elsewhere. This applies to those people living in the research area of Thon Village.

The Phuan people living in Ta Talat are descendants of immigrants who moved to Suphanburi Province in one of three waves. A forcible relocation 
programme led by the Thai army in 1779 caused the first wave, the second wave was due to a temporary labour programme recruiting sugar palm farmers in 1825 , and the third wave was part of a voluntary immigration movement under the favourable government of Rama III in 1829. The three groups settled near to one another and their settlements combined to form the Phuan community of Suphanburi, which now stretches over seven sub-districts and comprises some 20,000 individuals.

The first Phuan people living in Mab Pla Kao Village moved circa 1827, during the reign of Rama III. At this time, the rebellion of Chao Anouvong of Vientiane had been crushed and the northern territories came under stricter control by Siam. The governor of Phetchaburi was granted a portion of the Phuan population to boost provincial labour and separate the potentially rebellious Lao peoples. In the first instance, the group settled near the Phetch River, however soon moved to more-suitable farming land.

\section{Language}

The Phuan people in each of the four communities maintain their ethnic language. However, it was noted by the researchers that there are distinct regional differences between the Phuan spoken in communities from different geographic locations in Thailand. These differences are heavily influenced by the version of Thai spoken in the surrounding area.

The Phuan people of Thung Hong Village speak the Phuan language, which is a member of the Tai language family, although both Lanna and Thai are used to communicate in daily life. Regardless, people of all ages understand the Phuan language. The official Thai spelling of the community and temple was changed during the government of Field Marshal Plaek Phibunsongkhram, when 17 Thai letters were rendered obsolete. The first letter was altered from the old 'hor-nok-hook' to be 'hor-hieb' (Juntanamalaga, 1988). When the government changed, the community's name was returned to its original spelling. The temple, which remained under the jurisdiction of the Ministry of Religion, did not revert. Consequently, the two have different spellings.

Like the members of Thung Hong Village, those living in Thon Village also speak the Phuan language, although the vocabulary and accent is similar to the Isan dialect spoken throughout the northeastern region of Thailand, rather than the Lanna of the North. Standard Thai language is used to communicate with official institutions, government organisations and, increasingly, in schools. Regardless, people of all ages understand the Phuan language - "we all speak to 
each other in Phuan" (Nattaporn Chaininwong, personal communication, 27 $7^{\text {th }}$ June 2018).

The Ta Talat community of Suphanburi in Central Thailand was the only group to maintain the language in its written form. The language is preserved in the written manuals and books of Mr. Somboon Homsuwan. The spoken language is used by most families in the community, and is especially popular among adults and the elderly. The accent is very similar to Central Thai and is comprehensible to Thai speakers, with a few Thai words taking alternative meanings in the Phuan language. There are two forms of written Phuan language in the community, religious script and secular script. The religious script is called tophuan and uses characters found in the former Lanna script of Northern Thailand, which is derived from the Mon, Burmese and Shan languages. It is used to write religious stories, sermons and prayers. The secular script is based on Lao script and is used for verses, tales, fables, epics and poems.

The Phuan language is spoken in Phetchaburi by members of the Mab Pla Kao community, although given the location of Phetchaburi on the northern tip of Southern Thailand, there is a distinctive accent and vocabulary from the Phuan spoken in the other communities studied. As with each of the other villages, Thai is used for formal communication with government and private organisations, as well as in schools.

In all four communities, it was found that use of the Phuan language is declining in the younger generations as youths speak and write standard Thai more frequently for formal interactions. According to members of the community, the two major reasons for this shift are education and technology. The Phuan language has suffered because it is not the official language of education and, according to Damrong Tongkamhong, "it is not even taught or recorded at all" in Phuan schools (personal communication, $30^{\text {th }}$ June 2018). Furthermore, popular social media channels, movies and music are all in Thai or international languages, not Phuan. In the past, younger Phuan people were embarrassed to speak their ethnic language. This is no longer the case because there is a realisation of the importance of the maintenance of Phuan ethnic identity, as well as recognition of a wider provincial and national Phuan community. However, a result of the previously negative image of the language is a dwindling population of speakers under the age of 30 .

\section{Cuisine}

There are many local Phuan recipes. In each of the four villages, fermented fish is popular as a seasoning ingredient in many traditional recipes, although the fish 
used is determined by the species found in the surrounding environment. Dishes are invariably complex and time-consuming. The most famous local delicacies are regional. For example, the khanom chin rice-noodle dish is a well-known taste of Phetchaburi Province, whilst the most important ceremonial dish in the Northeast is kao nga ko, a sweet sticky rice and sesame seed dessert. The cleanliness of the food is extremely important to the villagers and other Phuan specialties include jaew ma den (a spicy tomato dipping sauce), pam kai (a Phuan version of poached eggs), pla den (a kind of local sashimi) and fo kiad (a spicy frog salad). In Thon village, the cuisine is similar to standard Northeastern Thai fare, but the Phuan people are more meticulous in their preparation and insistence that food is cooked before being eaten. Local villager Srima Warint attributes the similarities between Phuan cuisine and Isan food to the origins of the Phuan people - "because we all descend from people who once lived in the Laos Kingdoms, our foods are almost the same" (personal communication, $27^{\text {th }}$ June 2018).

\section{Clothing}

Traditionally, Phuan men wear short-sleeved shirts tied with cloth strands attached to each side (Figure 1). When worn, the strands are tied together to form a belt. This style has been developed into button-up shirts, which are called suea gui heng because of their resemblance to traditional Chinese shirts bearing the same name in Thai. The trousers are wide-legged, made from traditional indigo mor hom fabric and held up by a loincloth tied around the waist. The loincloth also serves multiple functions in the daily life of a Phuan man, such as shielding against the sun on a hot day or wiping sweat from the forehead.

Women wear a black and red patterned sarong, locally called a pa sin lae. This is worn with a round-necked, long-sleeved black shirt, which is fastened by buttons. Women also wear a white shoulder cloth. Married women wear sarongs with a red band at both the base and the hip ( pa sin lae song kiw). Unmarried women wear sarongs with a single red band at the hem ( $p a$ sin lae nueng kiw).

Even though modern clothing is now common, there is a culture of restoration of traditional fabrics. This is especially true in Thon village, where the local community has created its own brand of Thai Phuan clothing ('Puan Kaler') (Figure 2). The clothes are made from cotton and handwoven in the ikat style. The fabric patterns are developed to pay homage to the Phuan traditions and the brand intention is to create a geographic identifier for the Phuan people of Udon Thani. The villagers have now found a niche market to sell their traditional clothing, which was originally only woven to be worn within the community. Actually, Jon Meunghon, an 84-year-old resident of Thon village, complained during an 
interview that formerly "everyone in the community could weave. It was what we did!" (personal communication, $28^{\text {th }}$ June 2018). Although the craft is not as widespread, the revival has at least refreshed the local relationship with weaving culture. The group has now completed the copyright process for their traditional designs and is currently working on 20 additional designs and 9 colours from natural dyes.

Much like the current case of Thon village, the Phuan people of Phetchaburi formerly had a unique weaving and fashion culture. Over time however, this has disappeared and the Phuan people have been forced to invent their own unique outfits that can differentiate them from other ethnic groups at provincial culture exhibitions. The traditional costume of the Tai Song Dam is particularly similar to the former Phuan clothing. In response, the community at Mab Pla Kao developed five sets of costumes for women with authentic patterns along the base and hip of the sarong and new male styles (Figure 3).

There was a reaction to the creation of a new fashion identity for the Phuan villagers of Mab Pla Kao. Dissenting voices expressed their doubt over the need for a new identity given the old one had long since died, and they also questioned the wisdom of encouraging otherwise busy agriculturalists to spend long hours creating new fabrics. Thus, the initial obstacle was building acceptance from outside and within the community. Thanks to the commitment of certain individuals, the new Phuan designs went ahead with private funding. Later, the locals received financial support from the Map Pla Khao Sub-District Administrative Organisation, which covered much of the expense. After the principal designer ended their association with the Sub-district Administrative Organisation in 1997, they founded their own fabric business in the community for creating new Phuan designs. This also became a vehicle for creating awareness of Phuan culture and disseminating the origin story of the Phetchaburi Phuan designs. When the business and production of the dresses had become established, students and academics came to learn more about the creation of the new Phuan identity through dress. There were also activities to promote tourism, budget support for the construction of a textile mill and employment of an indigenous Tai Song Dam weaver to teach members of the community how to weave. However, because there is no interest in weaving within the community and no supporting budget, the mill is not currently operational.

Due to a conflict that arose in connection with the modification of the Phuan costume, representatives of the community temple, school, academic institutions, the National Thai Phuan Association of Thailand and local community elders signed a declaration relating to the Phuan fabric identity. This 
declaration stated that the new costumes may no longer be branded in the name of the Phuan people of Phetchaburi Province. At present, these designs are well known and have gained wider acceptance beyond Phetchaburi. Yet despite this external acceptance, people within the community rarely wear these supposedly indigenous costumes. This is partly due to the high price of the costumes in comparison to the poor economic status of the villagers, but also the limited opportunities for people in a local farming community to dress up for ceremonial activities: "They are too expensive and I'm hardly going to pay that much on a costume I'd only wear to plant rice!" (Supak Ponprasert, personal communication, $8^{\text {th }}$ June 2018). The villagers place little importance on these new clothing designs, and only wear them if required at provincial exhibitions.

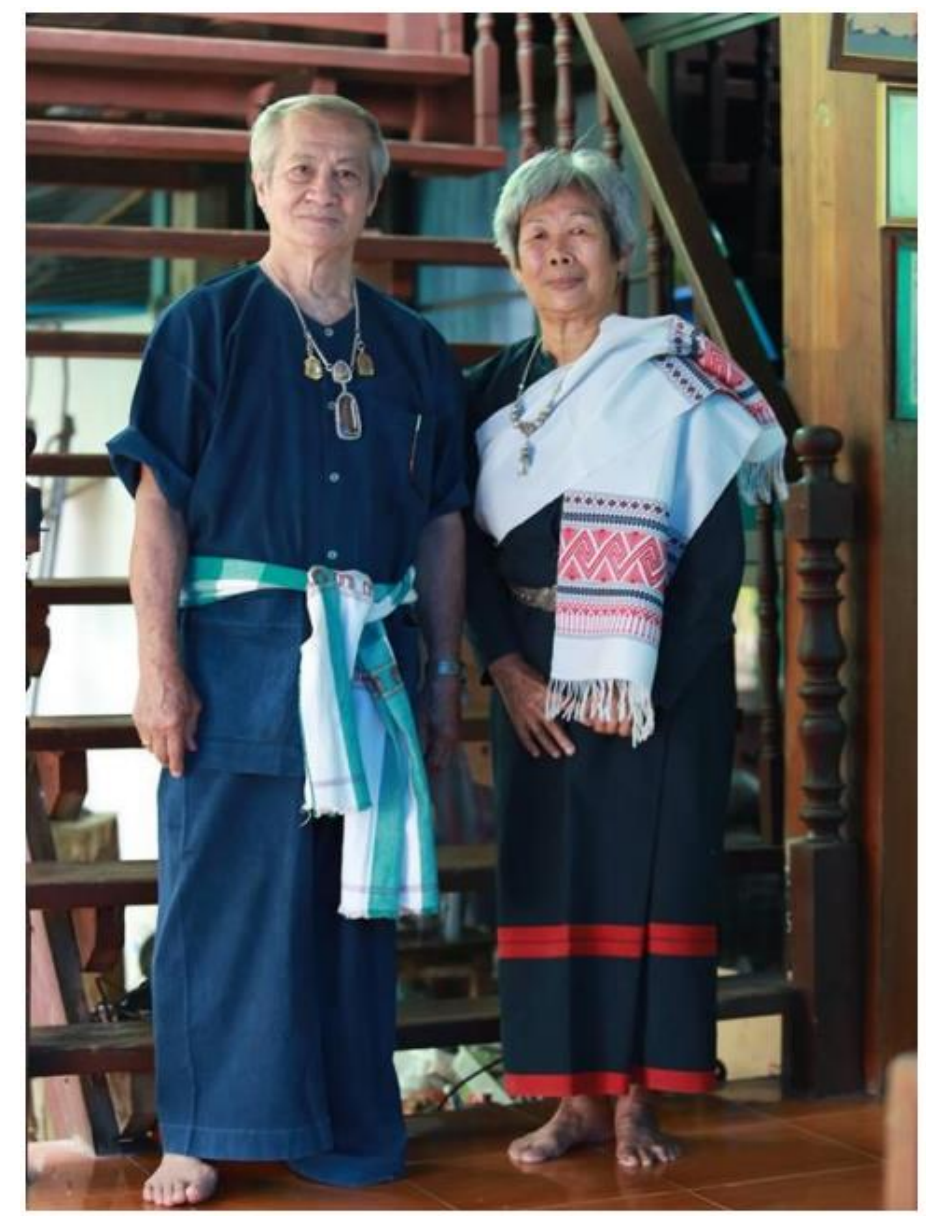

Figure 1: Traditional Phuan Clothing of Thung Hong Village (Source: Karapan and Susuwan, 2021.) 

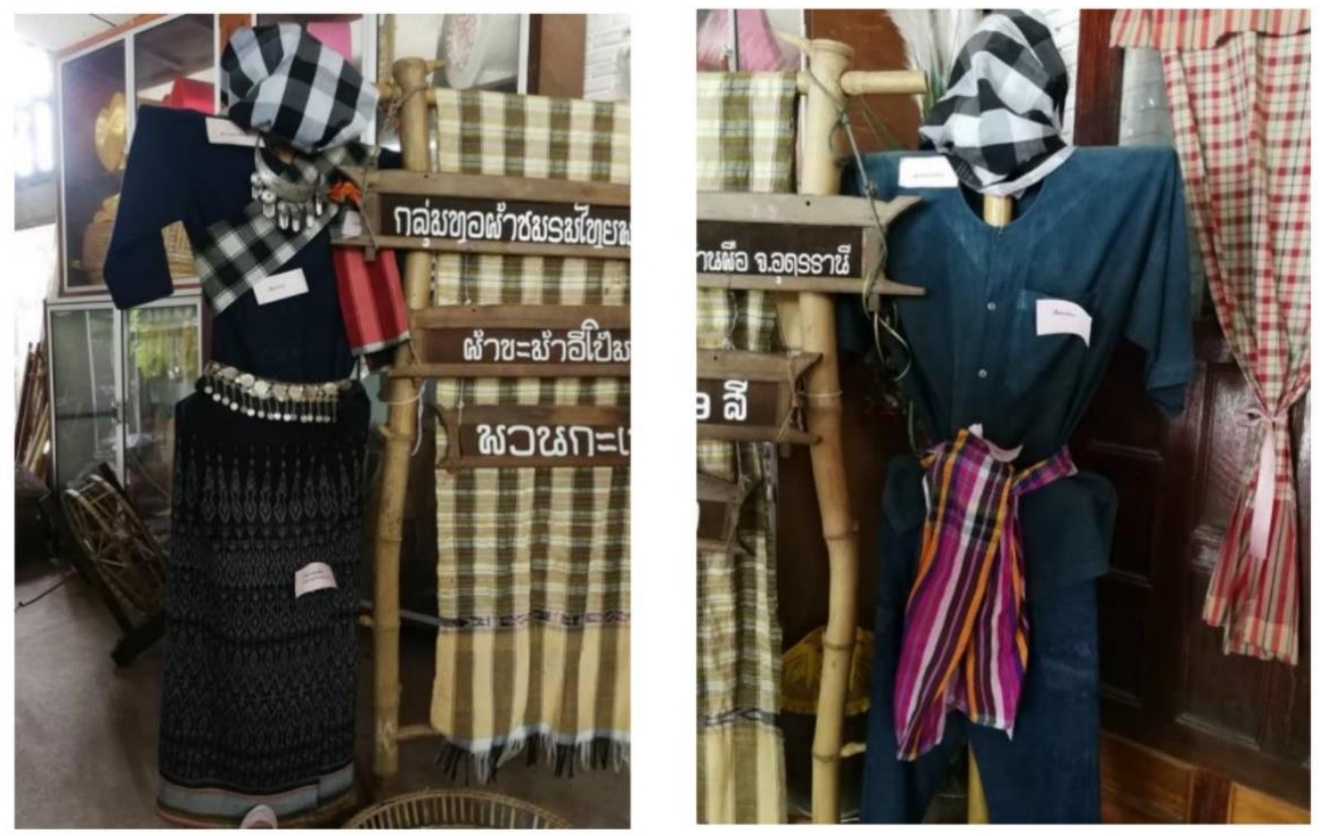

Figure 2: Traditional Phuan Clothing of Thon Village

(Source: Karapan and Susuwan, 2021.)

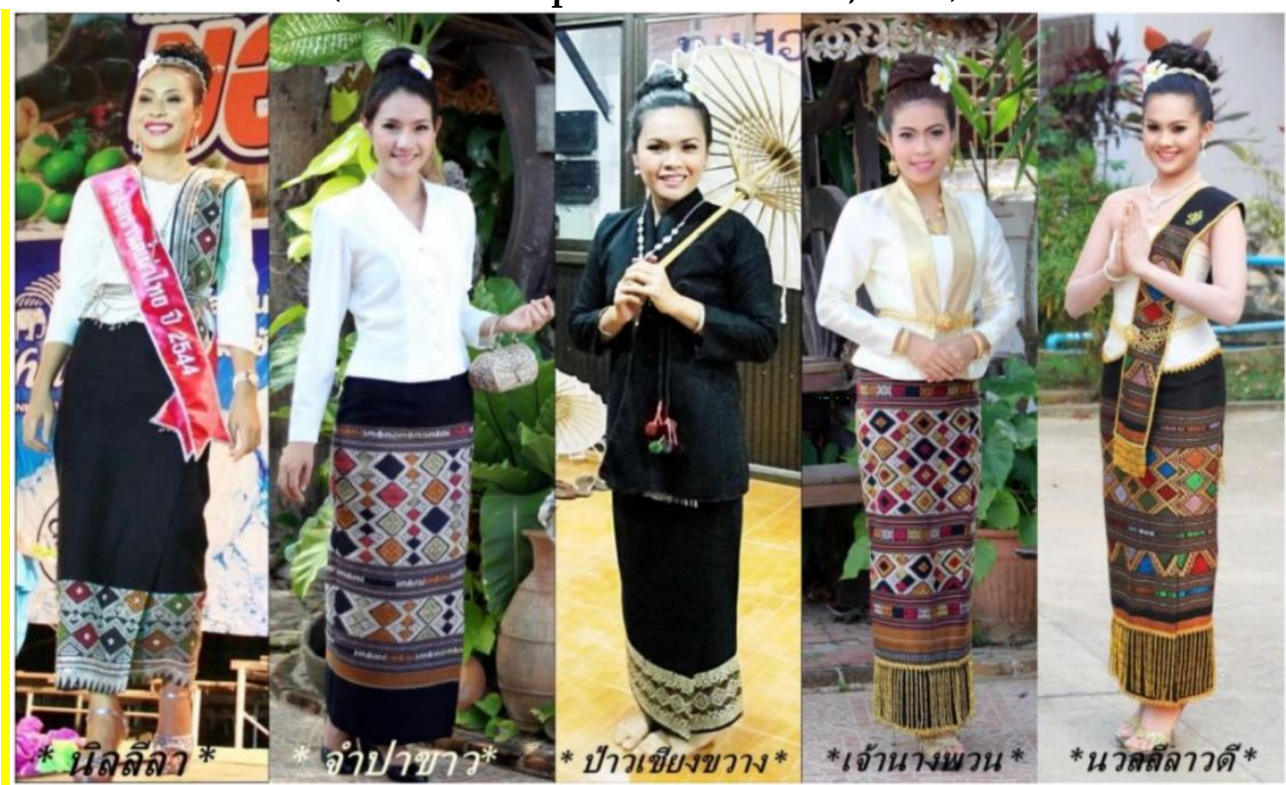

Figure 3: New Clothing Styles Created in the Name of the Phuan Identity in Phetchaburi Province

(Source: Karapan and Susuwan, 2021.) 


\section{Customs and Lifestyle}

The most important Phuan tradition is the kam fa festival, a merit-making custom inherited from Xiangkhouang to worship the sky god Phaya Tan. People pray for rainfall, the smooth passage of the seasons and safety in their everyday lives. In Phrae, this festival was practiced when the Phuan people first arrived and has become an important provincial tradition. During the daylong ceremony, everyone in the village must refrain from any manual labour. All tools should be packed away, leaving only equipment for cookery. It is believed that if the person does not obey the sky, the sky will retaliate. During kam fa, the eldest member of each family also makes an announcement to the working animals and pets to encourage them to keep working hard and to reassure them that they will be cared for. This is an important ritual for the eldest members of the community, as indicated by 92 -year-old Muen Banlor, "It gives us elders a sense of place in the village. We are still important" (personal communication, $15^{\text {th }}$ May 2018).

The tradition of kam fa has seen significant modifications in Phrae. Currently, it is considered a provincial cultural tourist attraction. Since 2002, the ceremony has moved from the Yom riverbank to Tha Nong Klang. An official ceremony was held at the Thung Hong Sub-District Administration Organisation sports field from 14-16 February 2002 and billed as the first of its kind. Four years later on 5th September 2006, a foundation stone was laid for the construction of the Chomphu Kasat Xiangkhouang memorial at the Thung Hong sports field. The statue was cast at the Chiang Mai Province foundry and installed on Sunday, 11 March 2007 during an elaborate local ceremony. Henceforth, the worship ritual of kam fa has increased in duration to three days and three nights, and now includes a parade, and traditional dance show, sports competitions, and cultural demonstrations to highlight the original lifestyle of the Phuan people. The Phrae provincial governor is invited annually to open the ceremony.

The Phuan adhere to the 12 heet 14 kong life principles held by the Isan people and other Thai-Lao ethnic groups of the region. In this respect, the beliefs, way of life, society, culture and traditions of the Phuan are similar to those of Isan people but there are some differences. Originally, the Thai-Phuan Association respected spirits and followed protective rituals. Some of these continue among the elderly in the present day, although the younger generations practice Buddhism. Music has developed in a similar way and, while the traditional music of the Phuan people is slow and rhythmic, modern numbers are faster and more frantic. They recount stories of the past and are based on the original songs from Xiangkhouang. 
From 2007-2018, there was a drive to publicise the Thai Phuan culture and traditions in Thon Village, welcoming outsiders to participate in activities. At first, members of the community collaborated with Thai Phuan people from other provinces at cultural events. Then, they enlisted the help of private government agencies to promote the arts and culture of the Phuan people. This generated a sense of local pride and realisation of the importance of cultural conservation among the Thon villagers, who now embrace a culture of preservation and transmission of traditions, art and local wisdom. There is a local knowledge centre for conservation and dissemination of local lifestyle, as well as activities in the community to encourage locals to adopt a subsistence and self-sufficient lifestyle.

The people of Ta Talat village in Suphanburi reciprocate this attitude. They play an important role in tourist activities on a provincial level and create interest in the province by hosting performances and cultural exhibitions to highlight the unique indigenous heritage of the area. Not only does this create an additional layer of importance for the Phuan people, it is also a tool to conserve, raise awareness of and promote the Phuan culture. By conforming to the demands of the tourism market, Phuan people have also adapted their traditions to modern society by creating new costume designs. They have also developed the equipment used in traditional ceremonies so that materials can be purchased conveniently and cheaply. The benefits are twofold: 1 ) There is no laborious and time-consuming production process; 2) Equipment can be donated to the temple once used during the ceremonies.

The Phuan have been forced to adapt in order to thrive in their new surroundings. In addition to the Phuan people living in Ban Phue, there are Chinese, Vietnamese, Lao Wiang, Lao Phu Khang and Isan people also living in the area. As the Phuan people are the most numerous, they control the local economy; however, the multiculturalism has resulted in some necessary changes. Most notably, the main Phuan shrine has become a multipurpose structure also worshipped by the local Chinese people (Figure 4). Phuan and Chinese rituals are both held at the shrine, just on different days. 

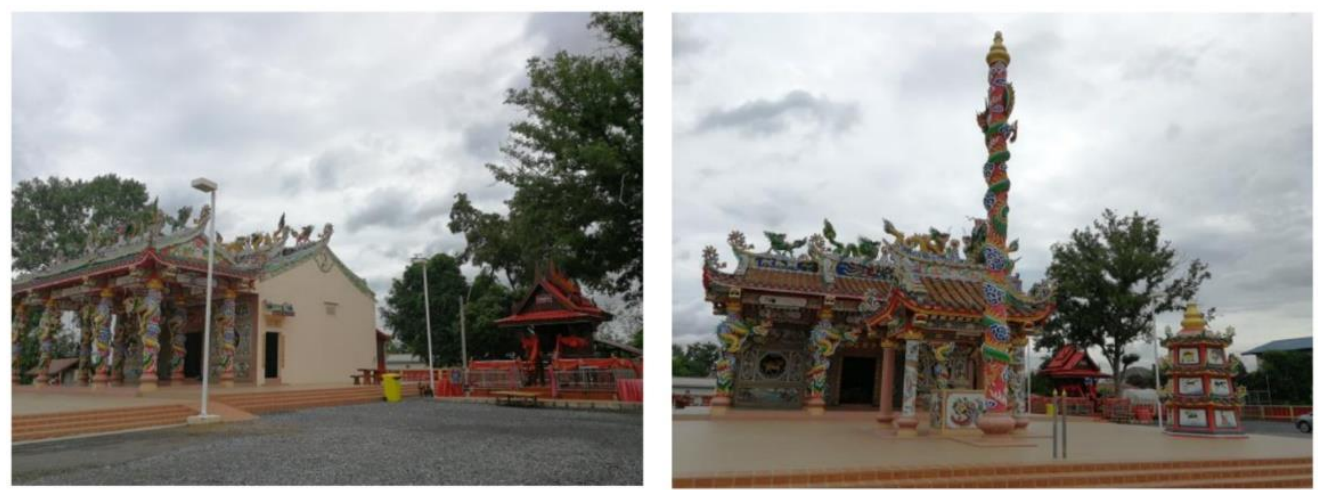

Figure 4: The Shared Shrine Site at Ban Phue Community, Udon Thani Province (Source: Karapan and Susuwan, 2021.)

The Phuan inhabitants of Mab Pla Kao are perhaps the most assimilated group given their proximity to Bangkok and more intense exposure to mainstream Thai culture. Consequently, their traditional customs are very similar to the central Thai culture, with a few minor exceptions. Biao Kampeng, an 83-year-old elder of the village feels that "to be honest, we are not really very Phuan at all any more, especially the youngsters" (personal communication, $30^{\text {th }}$ June 2018). For most of the villagers, modern cultural practices have been in place for as long as they can remember, with very little, if any changes.

In all villages, the main profession is agriculture, which is helped by the favourable soil conditions and reliable irrigation system that make it possible to farm throughout the year. Organic bananas (pisang awak and Cavendish) are important products for the Phuan people of Mab Pla Kao, who export large quantities to Japan. The bananas are grown on a 650-rai area of land, which is farmed by certified members of the local agricultural cooperative. In this community, farming is a priority, which is another reason why cultural tourism has not taken off.

\section{Phuan Ethnic Inheritance}

The Chaloemrat Culture Centre has been created in Thung Hong Village, which plays an important role in the succession of Thai Phuan culture. Activities are organised by the centre to transmit knowledge, heritage and cultural wisdom. These facilitate the conservation of Phuan customs through cooperation with groups from various sectors and build relationships between government agencies, the private sector and individuals interested in the development of 
intellectual heritage and the creative economy. A Thung Hong youth group has established an exhibition room for local people, especially youth, to learn local Phuan cooking, weaving, performing arts and customs.

In Thon Village, the central driver of inheritance remains the local chapter of the Thai Phuan Association, who coordinate activities between villagers in the district and government agencies to help preserve traditions and support inheritance among the younger generations.

In Ta Talat Village, people strictly adhere to the 12 heet 14 kong traditions, but there has been a concerted effort in recent times to create written records of the practices, rituals and beliefs that have been passed down from generation to generation. The community receives support from the government in organising important traditions.

The Phuan people of Mab Pla Kao Village encourage inheritance by teaching their children that ancestral spirits become angels to protect the community. If the children do not adhere to the customs, they are told that this will cause distress to the community. Stories of the past are also presented to outsiders at exhibitions, especially through the newly designed costumes.

\section{Discussion}

The dominant national culture has played an intentionally and unintentionally large part in the development of minority cultures throughout Thailand. Caused by their proximity to Central Thai communities, Phuan people have adjusted their lifestyle and social patterns in order to become increasingly well integrated in Thai society (Panin, 2010). These alterations extend to the modification of houses and their surroundings, which includes erection of boundary walls around properties, reduction of communal space and transformation of traditionally communal and recreational space under the stilt-houses into a space for economic practices (Sattayakorn, 2012). In the present study, the changing character of community space is best exemplified by the sharing of the shrine at Ban Phue, Udon Thani between the Phuan and the Chinese people.

Although Phuan groups across Thailand share very similar cultural practices and belief systems, there are regional differences that have been influenced by the surrounding environmental context of each community (Boonsom, 2017). For example, the vocabulary used by the four Phuan communities shares similarities with other locally spoken languages - Lanna in the North, Isan in the Northeast and standard Thai in Central Thailand. Differences in language tone were also found between the Phuan groups of Udon Thani and Nong Khai, which have been attributed to influences from the surrounding 
environment, as well as different paths of evolution caused by the geographic distance between the groups (Singsawat, 2017).

In an analysis of hand-woven Phuan textiles in three different areas, Boonsom concluded that Phuan textiles reveal the identity of the indigenous group and demonstrate socio-cultural dynamism that has enabled the Phuan people to play a major role in Thai society and economy (Boonsom, 2017). However, results from the current study would suggest that caution should be exercised when considering fabrics produced for cultural exhibitions and tourism. The experiences of the Phuan people in Phetchaburi highlight the dangers of staged authenticity that creates too much of a divergence between cultural stereotypes and the traditions upon which they are based. Moreover, the benefits that the Phuan people have reaped from this 'major role' in boosting the Thai economy are negligible.

The Phuan people value traditions highly, especially the kam fa festival. The ceremony is particularly closely observed by the Phuan people of Phrae province, where it has been promoted as a cultural tourist attraction, and is recognised by those living in Udon Thani and Suphanburi. However, the Phuan people in Phetchaburi no longer have established kam fa traditions, which may be a by-product of their proximity to the capital, Bangkok, and its centralised Thaiification. It is possible, given the absence of $\mathrm{kam} \mathrm{fa}$ and traditional textile culture among the Phuan of Phetchaburi that the residents of this area no longer consider themselves (and therefore can no longer be considered) the same ethnic group as the Phuan of the North or Northwest (van Roy, 2018). Further study is merited before such drastic conclusions can be reached but there are certainly signs that Thai-ification has worked better in Phetchaburi than elsewhere.

Studies of the kam fa festival have found tourist events to be laden with prejudices of the Phuan people that are not consistent with inherited traditions. Although these have contributed to the success of the festival by tapping into tourist attraction to 'otherness', they do not present a true picture of the Phuan people (Aneksuk \& Ruangkamnerd, 2010). Domestic scholarship has overwhelmingly emphasised the need for local adaptation to tourist demand to facilitate an improved tourism experience that will in turn stimulate conservation. Suggestions include external government intervention and investment (Panupat, Gulthawatvichai \& Karnjanakit, 2019), increased use of technology and bilingual multimedia (Phobphison \& Theerapappisit, 2018). There has been success through reinvention of the past (Wittayapak, 2003). However, cultural preservation must not be pursued at the expense of cultural authenticity. There is a real danger that cultural exhibitions depicting the customs of the Phuan are creating a catalogue of 
'invented traditions' in much the same way as happened with the Mon and Akha people (Agostini, 2018; Wongpolganan, 2007). One need only cite the reaction of the villagers in Phetchaburi to the imposed ethnic costumes as evidence of this.

However, novelty is not always undesirable. It would be hypocritical to argue against the cultural time-freeze created by stereotypes in the name of tourism, only to promote preservation of a stagnant ethnic culture not affected by the increasingly global world. The point is that culture should be permitted to evolve organically with the participation and acceptance of the members of that culture. The people of Suphanburi practice everyday customs with great intensity and there are many traditions within the community. In Udon Thani and Phrae Provinces, the Phuan communities are conscious and proud of their Phuan identity and actively disseminate knowledge to create awareness of their culture at the provincial, national and international level. The researchers feel that the Phuan people in each community have developed everyday activities alongside local customs to ensure their culture is maintained and recognised by external groups, especially tourists. This provides tangible economic benefit for the group and should not be casually dismissed as a negative by-product of globalisation. However, in order to maintain a unique and authentic identity, more community members need to become invested in cultural conservation.

Slow integration has been caused by a lack of cooperation between the Phuan people and government institutions, with fault on both sides. Some government officials have been accused of hostility towards the ethnic group, whilst some Phuan people have refused assistance from mainstream organisations (Aneksuk \& Ruangkamnerd, 2010). There should not be a top-down organisation of cultural activities. Rather, communities should participate with local institutions to create an authentic Phuan experience. Importantly, the conservation process "must not adversely affect the community's socio-economic structure too severely" (Prompayuka \& Chairattananon, 2016, p. 240).

Traditional Phuan culture is becoming more diluted due to rural-urban migration of working-age adults (Panupat, Gulthawatvichai \& Karnjanakit, 2019; Yokanya, 2018). If the Phuan communities can enjoy economic success stimulated by cultural tourism based on their traditions, there will be more attractive employment opportunities at home and less need for younger people to migrate. This will in turn encourage a culture of preservation and pride in Phuan identity. 


\section{Acknowledgement}

The authors would like to thank Princess Maha Chakri Sirindhorn Anthropology Centre (Public Organisation) for supporting this research project. The grant number for this project was SAC61C005.

\section{References}

Agostini, A. (2018). Christianity, Ancestor Worship, and Cultural Revitalisation among Akha Communities in the Upper Mekong Region. Thammasat Review, 21(2), 1-16.

Alexander, S., \& McCargo, D. (2014). Diglossia and Identity in Northeast Thailand: Linguistic, Social, and Political Hierarchy. Journal of Sociolinguistics, 18(1), 60-86.

Aneksuk, B., \& Ruangkamnerd, A. (2010). Dynamic of Boon Kam Fa Tradition of Phuan Ethnic Group in the Thailand Tourism Context. WIT Transactions on Ecology and the Environment, 139(1), 411-422.

Ar-romsuk, T. (1978). A Comparative Study of the Tones of Spoken Words between Phuan Dialect and Standard Thai (Master's thesis), Srinakharinwirot University, Bangkok, Thailand.

Boonsom, W. (2017). A Comparison of Symbolic Textile Patterns among the Lao Phuan in Chieng Kwang, Lao People's Democratic Republic; the Thai Phuan in Ban Mi, Lopburi Province; and the Thai Phuan in Hat Siao, Sukhothai Province, Thailand. Journal of Mekong Societies, 13(1), 171-187.

Breazeale, K. (1975). The Integration of the Lao States into the Thai Kingdom (Ph.D. thesis), University of Oxford, Oxford, United Kingdom.

Breazeale, K. (2012). Historical Population Movements in North and Northeast Thailand. Journal of Population and Social Studies [JPSS], 20(2), 109-144.

Breazeale, K., \& Smuckarn, S. (1988). A Culture in Search of Survival: The Phuan of Thailand and Laos. New Haven: Yale University Southeast Asia Studies.

Bunnag, Tej. (1968). The Provincial Administration of Siam from 1892 to 1915 (Ph.D. thesis), University of Oxford, Oxford, United Kingdom.

Burns, P. (2001). Brief Encounters: Culture, Tourism and the Local-Global Nexus. In S. Wahab \& C. Cooper (Eds.), Tourism in the Age of Globalisation (pp. 290305). London: Routledge.

Burusapatana, K., \& Atipas, P. (1988). Thai Government Policies on Minorities. Asian Journal of Social Science, 16(1), 47-60. 
Chantavanich, S. (2004). Qualitative Research Methods. Bangkok: Chulalongkorn University Press.

Diller, A. (2002). What Makes Central Thai a National Language? In C. Reynolds (Ed.), National Identity and Its Defenders: Thailand Today (pp. 71-107). Bangkok: Silkworm.

Dolezal, C. (2011). Community-Based Tourism in Thailand: (Dis-)Illusions of Authenticity and the Necessity for Dynamic Concepts of Culture and Power. ASEAS - Austrian Journal of South-East Asian Studies, 4(1), 129-138.

Draper, J., Garzoli, J., Kamnuansilpa, P., Lefferts, L., Mitchell, J., \& Songkünnatham, P. (2019). The Thai Lao - Thailand's Largest Unrecognised Transboundary National Ethnicity. Nations and Nationalism, 25(4), 11311152.

Draper, J., \& Selway, J. S. (2019). A New Dataset on Horizontal Structural Ethnic Inequalities in Thailand in Order to Address Sustainable Development Goal 10. Social Indicators Research, 141(1), 275-297.

Enfield, N. (2002). How to Define 'Lao', 'Thai' and 'Isan' Language? A View from Linguistic Science. Tai Culture, 7(1), 62-67.

Hesse-Swain, C. (2011). Speaking in Thai, Dreaming in Isan: Popular Thai Television and Emerging Identities of Lao Isan Youth Living in Northeast Thailand (Ph.D. thesis), Edith Cowan University, Perth, Australia.

Iijima, A. (2018). The Invention of "Isan" History. Journal of the Siam Society, 106(1), 171-200.

Ivanovic, M. (2008). Cultural Tourism. Cape Town: Juta \& Company Ltd.

Juntanamalaga, P. (1988). Thai or Siam? Names, 36(1-2), 69-84.

Kashima, Y. (2014). How Can You Capture Cultural Dynamics? Frontiers in Psychology, 5, 995. https://doi.org/10.3389/fpsyg.2014.00995

Keyes, C. (2014). Finding Their Voice: Northeastern Villagers and the Thai State. Chiang Mai: Silkworm.

Lefferts, L., \& Cate, S. (2012). Theravada Buddhism and Political Engagement Among the Thai-Lao of North East Thailand. South East Asia Research, 20(3), 329-341.

Lertcharnrit, T., \& Niyomsap, N. (2020). Heritage Management, Education, and Community Involvement in Thailand: A Central Thai Community Case. Journal of Community Archaeology \& Heritage, 7(3), 187-197. https://doi.org/10.1080/20518196.2020.1767378

Makpa, P. (2017). Creative Dancing Arts and Promotion of Cultural Identity of the Thai Puan People in Ban Bung Khe, Nong Saeng Sub-district, Pakplee 
District, Nakhon Nayok Province. Institute of Culture and Arts Journal, 19(1), 72-81.

McCargo, D., \& Hongladarom, K. (2004). Contesting Isan-ness: Discourse and Politics in the Northeast of Thailand. Asian Ethnicity, 5(2), 219-234.

Panin, O. (2010). First Year Progress Report of Holistic Study for the Adaptability in the Different Context of Tai-Lao Ethnic in the Central Region Basin of Thailand. Bangkok: Kasetsart University, Thailand Research Fund and Office of the Higher Education Commission.

Panupat, C., Gulthawatvichai, T., \& Karnjanakit, S. (2019). Development Guideline for Cultural Tourism of Thai Ethnic Group: A Case of Thai-Puan Community. PSAKU International Journal of Interdisciplinary Research, 8(1), 234-242.

Phobphison, P.-U., \& Theerapappisit, P. (2018). Interpreting Cultural Heritage for Non-Thai Visitors in the Hat Siao Community, Sukhothai Province, Thailand (Ph.D. thesis), Silpakorn University, Bangkok, Thailand.

Prompayuk, S., \& Chairattananon, P. (2016). Preservation of Cultural Heritage Community: Cases of Thailand and Developed Countries. Procedia-Social and Behavioural Sciences, 234(1), 239-243.

Sangchumnong, A, \& Kozak, M. (2018). Sustainable Cultural Heritage Tourism at Ban Wangka Village, Thailand. Anatolia, 29(2), 183-193.

Sattayakorn, S. (2012). Space as a Place for Social Interaction: A Case Study of TaiLao Communities. Journal of Architectural/Planning Research and Studies (JARS), 9(1), 13-26.

Sermcheep, S. (2012). Thailand's Inclusive Growth and Regional Economic Cooperation. East Asian Policy, 4(4), 46-55.

Singsawat, P. (2017). A Comparative Study of Phonology and Lexical Words of Phuan in Nong Khai and Udon Thani, Thailand. Chophayom Journal, 28(3), 80-87.

Sirasoonthorn, P., Satean, G., Khamunee, W., \& Pirasan, J. (2016). A Development of the Logistic Creative Community Economy for the Promotion of Participatory Cultural Tourism: A Case of Cultural World Heritage, Thailand. Journal of Community Development Research (Humanities and Social Sciences), 9(3), 10-20.

Taylor, J. (2001). Authenticity and Sincerity in Tourism. Annals of Tourism Research, $28(1), 7-26$.

Tumad, S., \& Siriwong, P. (2017). The Life Narrative: Cultural Resource Management of the Thai-Puan Ethnic Group. Institute of Culture and Arts Journal, 20(2), 100-115. 
van der Duim, R., Peters, K., \& Wearing, S. (2005). Planning Host and Guest Interactions: Moving Beyond the Empty Meeting Ground in African Encounters. Current Issues in Tourism, 8(4), 286-305

van Roy, E. (2009). Under Duress: Lao War Captives in Bangkok in the Nineteenth Century. The Journal of the Siam Society, 97(1), 43-68.

van Roy, E. (2018). Siamese Melting Pot. Bangkok: Flipside Digital Content Company.

Vichiranon, S., Sangoupong, W., Suthapannakul, R., \& Wangvanitchaphan, S. (2013). Being Phuan in Contemporary Society. Phra Nakhon: Rajamangala University of Technology.

Wittayapak, C. (2003, February 6-9). History, Identity, and Resource Struggles of the Ethnic Enclaves in Modern Thailand. Paper presented at the CRN Meeting ACLS Offices, New York, United States. Retrieved December 20, 2020, from http://archives.acls.org/programs/crn/network/meetings_nyc_wittayapak. htm

Wongpolganan, J. (2007). Mon Nationalism and the Invention of Traditions: The Case of the Mons in Their Diasporic Communities. Manusya: Journal of Humanities, 10(1), 50-71.

Yokanya, N. (2018). A Model Development of the Learning Society of Sustainable Language and Cultural Diversity in Phetchabun Province. Rommayasarn, 16(Special Issue), 159-182.

Cite this article (APA):

Karapan, R. \& Susuwan, P. (2001). Dynamics and adaptation of the Phuan ethnic group in Thailand. JATI-Journal of Southeast Asian Studies, 26(1), 141-162 